\title{
Wood preservation with gold hydroxyapatite system
}

\author{
Rodica-Mariana Ion ${ }^{1,2^{*}}$ (0), Tebello Nyokong ${ }^{3}$, Nnamdi Nwahara ${ }^{3}$, loana-Raluca Suica-Bunghez ${ }^{1}$, \\ Lorena lancu', Sofia Teodorescu ${ }^{4}$, loana Daniela Dulama ${ }^{4}$, Raluca Maria Stirbescu', Anca Gheboianu ${ }^{4}$ \\ and Ramona Marina Grigorescu'
}

\begin{abstract}
Over centuries, the external factors such as fire, low temperature, light or microbiological agents, act on the wood and induce some degradation processes, sometimes irreversible, identified by discoloration, fragility and unsightly appearance. Although there are numerous literature reports about different nanomaterials used for preservation and restoration of wood surfaces (calcium hydroxides, magnesium hydroxides, hydroxyapatite, or even organic resins as Paraloid B72), in this paper it is proposed a new system — gold hydroxyapatite (AuHAp), tested on the hazelnut wood samples (young and aged specimens), as a new solution for preservation of some wooden artifacts. This paper addresses a broad range of analytical methods: X-ray diffraction, UV-Vis spectrophotometry, Fourier transformed infrared spectroscopy, Raman spectroscopy, scanning electron microscopy with energy dispersive spectroscopy, chromatic parameters and hardness test. Also, humidity sorption/desorption measurements are used for humidity sorption and desorption evaluation. The adsorption and desorption tests determined the hydroscopic sorption properties of the wood specimens by measuring the mass of the specimens in equilibrium with air at a specific temperature and $\mathrm{RH}$. All the results concluded that after the application of the new system on the hazelnut wood surface, a well distributed and uniform layer consisting from AuHAp systems with a network aspect are observed, which covers the wood vessels and fibers, filling the voids and stopping the wood weathering process, more accentuated at aged wood than at the young species.
\end{abstract}

Keywords: Wood preservation, Hazelnut wood, Gold, AuHAp

\section{Introduction}

Wood is one of the oldest materials in the humanity history, deeply rooted in the consciousness of society through its material values and processing properties for tools or furniture objects [1]. It is an organic material which supports a continuous degradation and deterioration processes by action of fire, weathering, and various organisms [2]. Therefore, people are trying different methods of improving its durability. For stopping the degradation processes, the wood artifacts could undergo some conservation treatments with different compatible

\footnotetext{
*Correspondence: rodica_ion2000@yahoo.co.uk

1 Research Group "Evaluation and Conservation of Cultural Heritage", National R\&D Institute for Chemistry and Petrochemistry-ICECHIM, 202

Splaiul Independentei, 060021 Bucharest, Romania

Full list of author information is available at the end of the article
}

materials, to stabilize the wooden structure and avoid shrinkage and collapse and for a longer integrity of the object. A preservation material should obey the following rules: to remain stable over long periods of time; to be reversible; to penetrate and distribute evenly throughout the wood; to prevent dimensional changes and maintain the original appearance of the artefact; to be compatible with wood, or with other materials from the wooden system; to present reduced/no toxicity; to prevent biological degradation and acidification of the wood.

One of the major problems that affects the conservation state of wooden artifacts or artworks (paintings, icons) is the loss of the wood's structural resistance, due to xilophagous attacks or dehydration. During time, wood conservators and scientific researchers have proposed, tested and analyzed various materials and the solution on which the restorers' community 
agreed was the use of synthetic polymers, most often reported being Paraloid B67, Paraloid B72 and Paraloid B44 [3-7]. Even though these synthetic polymers have some advantages (reversibility, elasticity, commercially available etc.), they also have serious drawbacks: poor resistance to humidity, relatively weak bond with vitreous substrates and solvent hazards, its handling properties, difficulty to apply as an adhesive and to manipulate with precision $[8,9]$. In order to avoid its limitations, a new generation of the preservation materials is required.

During the last decades, the nanomaterials and nanotechnologies came into force in this area of cultural heritage, new and efficient systems being created and tested on different artifacts and works of art: metallic oxides and hydroxides $\left(\mathrm{ZnO}, \mathrm{TiO}_{2}, \mathrm{Ca}(\mathrm{OH})_{2}, \mathrm{Mg}(\mathrm{OH})_{2}\right.$, $\left.\mathrm{Ba}(\mathrm{OH})_{2}, \mathrm{Sr}(\mathrm{OH})_{2}\right)$ [10], metallic nanoparticles $(\mathrm{Au}, \mathrm{Ag}$, $\mathrm{Pt})$ [11], and very recently, hydroxyapatite (HAp) $\left(\mathrm{Ca}_{10}\right.$ $\left.\left(\mathrm{PO}_{4}\right)_{6}(\mathrm{OH})_{2}: \mathrm{Ca} / \mathrm{P}=1.67\right)$ [12].

Starting from the mention that the cellulose polysaccharides and the lignin part of wood (that contain phenol and methoxy groups), can generate noble metals nanoparticles by green synthesis [13], in this paper it is proposed a new nanomaterial AuHAp, synthesized by noble metals capacity to interact and replace Ca from HAp [14].

The methods found to produce AuHAp are not quite diverse [15-19], the Turkevich method or a variant of it being recognized as the most proper synthesis method for AuNP, similar with AgHAp synthesis already reported by our group [20]. The application of noble metals for wooden artifacts should obey its integrity and authenticity that mostly depend on the nature of the object to be treated, the type and condition of the materials, and the functional requirements of the object.

The hazelnut wood is used in different cult and decoration objects, furniture and even for different jewelries, that's why it's important to know how to preserve them and to stop the weathering process. Usually, the young wood is characterized by progressive increases in dimensions and changes in the cell characteristics and the pattern of cell arrangement. Also, the young wood cells are shorter than those of aged wood and some large microfibril angles are also associated with low tensile strength. The young wood is rougher and contains more splits and deeper lathe checks. By comparison, the aged wood appears more rigid and stronger than young wood, because is characterized by relatively constant cell size, well-developed structural patterns, and stable physical behavior. This is the reason which for an optimal solution for aged wood conservation is requested as the best among the solutions reported in the literature, avoiding their disadvantages and to keep their historic memorabilia in the best shape possible.
Under this context, the objectives of this paper is to create a new material-AuHAp-and to test it on the wood samples (young and aged specimens), in order to create a new solution for preservation of old artifacts.

This paper addresses a broad range of non-destructive or (micro)-destructive methods: X-ray diffraction (XRD), UV-Vis spectrophotometry, infrared spectroscopy Fourier transformed (FTIR), Raman spectroscopy, scanning electron microscopy with energy dispersive spectroscopy (SEM-EDS), chromatic parameters, hardness test, in order to correlate the properties of the new created nano-systems and their structural and interaction characteristics. Also, humidity sorption and desorption measurements have been registered and processed.

\section{Experimental part Wooden materials}

The hazelnut wood samples [from a young tree (about 10 years old)] without knots were selected for the experiments. In order to minimize shrinkage, swelling and cracking, small circular specimens with a diameter of $7.0 \mathrm{~mm}$ and thickness of $5 \mathrm{~mm}$ were used for the measurements. For wood aging, each wooden sample was cut in small circular slices and dried in the oven at $100{ }^{\circ} \mathrm{C}$ for $24 \mathrm{~h}$, in agreement with previous reports [20]. Both samples of young and aged wood were brushed with AuHAp suspension in isopropilic alcohol, as a environment friendly solvent.

\section{Nanoparticles preparation}

$\mathrm{HAuCl}_{4}$ was purchased from Sigma Aldrich and were used as stock reactants, without purification. Hydroxyapatite powder was prepared in the laboratory, in agreement with the literature's reports [21]. The new system AuHAp has been generated in situ on the wood surface, as follows: $20 \mathrm{~mL}$ of noble metal acid $\left(\mathrm{HAuCl}_{4}\right)$ dissolved in water, $20 \mathrm{~mL}$ HAp (hydroxyapatite) suspended in water have been added in a vessel where is already immersed a wood piece (Fig. 1). The whole solution has been kept in oven $\left(3 \mathrm{~h} / 60^{\circ} \mathrm{C}\right)$, then stored in the dark over night, at room temperature.

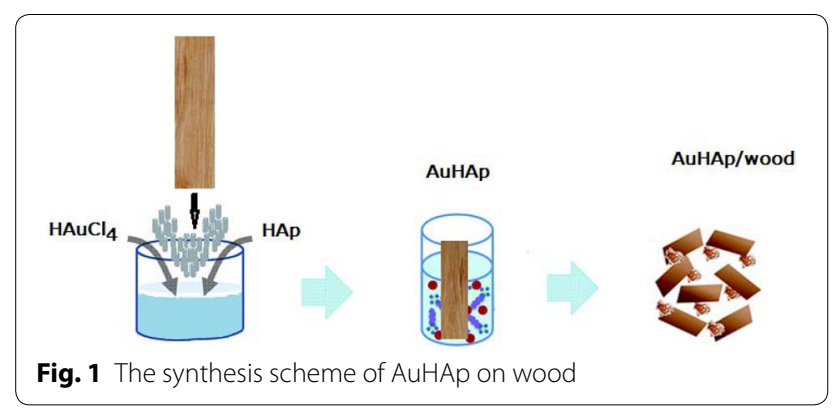


Meanwhile, the syntheses of the AuHAp systems were performed using a sonochemical homogeneous precipitation method:

$2 \mathrm{~mL}$ of tetrachloroauric acid $\left(\mathrm{HAuCl}_{4}\right)$ dissolved in water, 2 mL HAp (hydroxyapatite) have been subjected to ultrasonication on Bioblock Scientific $\left(30 \mathrm{~min} / 40{ }^{\circ} \mathrm{C}\right)$ ultrasound bath (UK), with the wood samples, kept in oven $\left(1 \mathrm{~h} / 60{ }^{\circ} \mathrm{C}\right)$, then stored in the dark over night, at room temperature. This method was previously developed for the formation of HAp particles and their composites with $\mathrm{Ag}$, called as post-synthesis [20,22].

\section{Characterization methods}

For UV-Vis absorption spectra a M 400 UV-VIS spectrophotometer (Carl Zeiss Jena, Germany), with monochromator and double beam spectrophotometer was used. For the absorption spectra of solutions $1 \mathrm{~cm}$ matched quartz cells were used. The solutions were measured in absorption mode and the spectra were recorded from 200 to $800 \mathrm{~nm}$ with a data interval of $1 \mathrm{~nm}$.

Fourier transformed infrared spectroscopy (ATR-FTIR) has been recorded with a Vertex 80 spectrometer (Bruker Optik GMBH, Germania) in the range of $4000-400 \mathrm{~cm}^{-1}$, 32 scan, resolution $4 \mathrm{~cm}^{-1}$, equipped with DRIFT accessory. Also, this apparatus could work in Attenuated Total Reflectance, ATR module.

For Raman spectra, a portable dual wavelength Raman (Rigaku, USA) analyzer equipped with with a standard diode-pumped, air-cooled Nd:YAG laser source (785 and $1064 \mathrm{~nm}$ ) with high sensitivity. This device does not require special preparation of samples; liquid and solid samples can be analyzed. For the measurements, a resolution of $4 \mathrm{~cm}^{-1}$ was used with a laser power of $252 \mathrm{~mW}$. Data were collected and processed with the software Opus 7.0 (Bruker Optics $\mathrm{GmbH}$ ). In order to avoid the local wood inhomogeneity, 5 measurements with 400 scans were performed.

The optical microscopy was performed with a Novex trinocular microscope (EUROMEX Microscopen B.V.HOLLAND) (at different magnifications: $40 \times, 100 \times$, $400 \times, 1000 \times)$.

Also, the optical microscopy has been recorded by a Primo Star ZEISS optical microscope that offers the possibility to investigate the samples in transmitted light at a magnification between $4 \times$ and $100 \times$. The equipment had attached a digital video camera (Axiocam 105) which, by the microscope software, allowed real-time data acquisition. The obtained images could easily be converted from 2D in 3D format through its software for a better viewing.

The scanning electron microscopy with energy dispersive spectroscopy (SEM-EDS) was obtained with a SU-70 (Hitachi, Japan) microscope, with a magnification range of $30 \times-800.000 \times$. SEM has been coupled with an energy dispersive spectrometer (EDS) which allows qualitative and quantitative analysis [from $\mathrm{Be}(\mathrm{Z}=4)$ to $\mathrm{Pu}(\mathrm{Z}=94)]$.

The diffraction data (XRD) for the dry powder were recorded on a X-ray diffractometer Rigaku Ultima IV, equipped with software for control, control, acquisition and data conversion, with the technical features: highresolution multimodal and multifunctional system with vertical goniometer $\theta / \theta$ ( $285 \mathrm{~mm}$ radius) in geometry G/9; automatic self-leveling via PC control; X-ray tube$\mathrm{Cu}$ anode $(2 \mathrm{~kW})$; detector $-\mathrm{NaI}$ with limitation $>700,000$ cps; operation in symmetrical and asymmetric geometry; Bragg-Brentano focused high-resolution geometry; geometry in the parallel beam, other specific configurations; width of the minimum pitch: on scan axes Ts: $0.001 \mathrm{~mm}, \theta \mathrm{D}, \theta \mathrm{S}$ : 0.00010; minimum scanning step on the $\theta \mathrm{D} / \theta \mathrm{S}$ axes in coupled mode 0.0002 and $\theta \mathrm{D} / \theta \mathrm{S}$ in independent mode: 0.0001-60; Software: PDXL 2.2. (processing), ICDD-PDF4+ 2016 (database).

Color measurements have been recorded with CM2600d spectrophotometer (KONICA MINOLTA) (Japan) under a D65 light source and an observer angle of $10^{\circ}$. The total color differences $\Delta \mathrm{E}^{*}{ }_{\mathrm{ab}}$ was calculated using the following formula [23]:

$$
\Delta \mathrm{E}_{\mathrm{ab}}^{*}=\left[\Delta \mathrm{L}^{* 2}+\Delta \mathrm{a}^{* 2}+\Delta \mathrm{b}^{* 2}\right]^{1 / 2}
$$

where $L^{*}$ is the lightness and $a^{*}$ and $b^{*}$ the color coordinates under any testing condition, and $\mathrm{L}_{0}{ }^{*}, \mathrm{a}_{0}{ }^{*}$, and $\mathrm{b}_{0}{ }^{*}$ the corresponding reference values obtained as the average the untreated specimens (Proceq) [24]. The measurements were carried out with the device Minolta Chroma-Meter CR-200, with diffuse illumination. Values recorded for each point are an average of three measurements.

The coloring density of the wood, in absolute value, in points, $\Delta \mathrm{b}$, was expressed according to the Eq. (2):

$$
\Delta \mathrm{b}=\left|\mathrm{b}_{\mathrm{x} \text { Treated }}-\mathrm{b}_{\mathrm{x} \text { Untreated }}\right|
$$

where $b_{x}$ treated $=$ color degree for treated wood, and $b_{x \text { untreated }}=$ color degree for untreated wood.

Depending on the degree of wood coloring in absolute terms, the following stability classes are specified: Stable $\leq 3$ of absolute value of $b_{x}$; Moderately stable $>3$ and $\leq 8$ of absolute value of $b_{x}$; Unstable $>8$ of absolute value of $b_{x}$.

Accelerate light aging has been tested for all types of samples of printing and writing paper exposed to a xenon-arc exposure apparatus, Xenotest S 150 from Atlas Instruments. The exposure was done with an air-cooled xenon lamp at an irradiance of $42 \mathrm{~W} / \mathrm{m}^{2}$ (wavelength in 
the range: $300-400 \mathrm{~nm}$ ), at $35^{\circ} \mathrm{C}$ temperature in the test chamber, at relative humidity $50 \%$, for $48 \mathrm{~h}$ [25]. The light flux causes photochemical reactions in wood that change its reflectance (brightness) and color. By comparing initial and final levels of these parameters against different criteria, a measured of optical stability is obtained.

The moisture content (M\%) was calculated at the equilibrium point according to the following Eq. (3):

$$
M \%=100 \frac{\left(W_{t}-W_{0}\right)}{W_{0}}
$$

where $\mathrm{W}_{\mathrm{t}}$ and $\mathrm{W}_{0}$ are the wet weight and the initial dry weight [26].

\section{Sorption/desorption curves (Hysteresis)}

The wood samples were located in a thermo-statically controlled chamber through which there was a constant flow of dry nitrogen gas and into which was mixed another flow of nitrogen containing water vapour. Small pieces of samples $(1.0 \pm 0.1 \mathrm{~g})$ were placed on the sample holder connected to a microbalance by a hanging wire. The sample was maintained at a constant $\mathrm{RH}$ until the rate change in mass was constant for $5 \mathrm{~min}$. The sorption/desorption relative humidity $(\mathrm{RH})$ has been changed from 50 to $95 \% \mathrm{RH}$ in the climate chamber. The mass change data were acquired every $30 \mathrm{~min}$. The adsorption and desorption tests determine the hydroscopic sorption properties of the specimens by measuring the mass of the specimens in equilibrium with air at a specific temperature and $\mathrm{RH}$, in good agreement with EN ISO 12571 (2000). During the entire experiment, the temperature $\left(25^{\circ} \mathrm{C}\right)$ was kept constant. For the adsorption test, the specimens were first dried to a constant mass and then exposed to a series of tests environments with $\mathrm{RH}$ varying. The amount of moisture adsorbed into the specimen per unit surface area in each $\mathrm{RH}$ is expressed in the adsorption curve. By plotting humidity percentage against time, the kinetic curves were obtained. The adsorption/desorption curves were fitted in Excel 10.0.

Hardness tests have been recorded with a SilverSchmidt Hammer L (Switzerland), adapted for wood hardness tests [24].

\section{Results and discussion}

\section{AuHAp preparation and characterization}

In order to characterize the new synthesized materialAuHAp-, the first step was their evaluation using X-ray diffraction analysis, Fig. 2. The diffractograms registered for HAp and its composite with $\mathrm{Au}$ have specific peaks corresponding to hydroxyapatite and gold. The XRD data showed peaks at the (002), (211), (310), (222), (213) and (321) regions specific for HAp and also for peaks of (111),

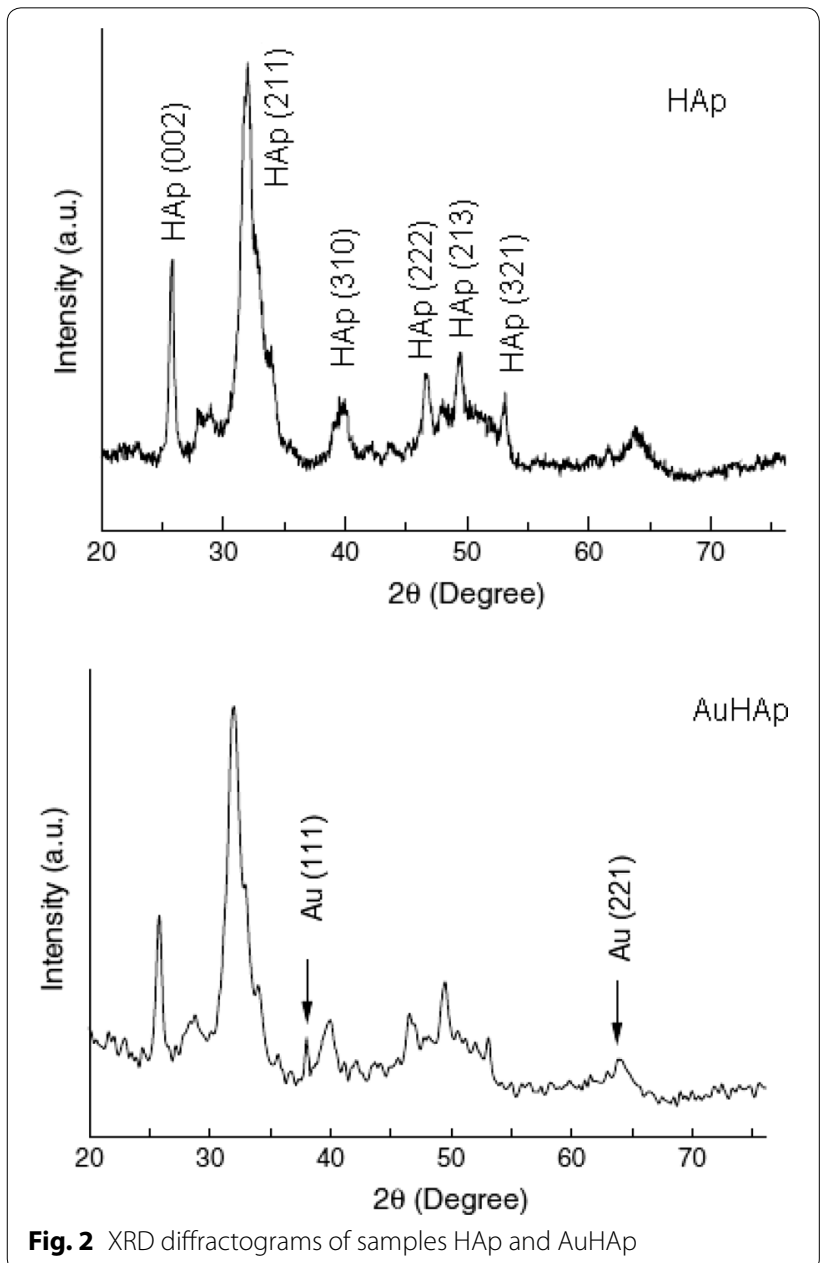

and (221) assigned to the $\mathrm{Au}$ (111) plane. The XRD analyses of the samples reveals the preservation of the peaks assigned to hydroxyapatite [27]. The diffraction patterns were very intense indicating that the synthesized AuHAp is crystalline. No other phases except HAp and Au were detected, which demonstrates that no decomposition of HAp has taken place during the synthesis of AuHAp.

EDS results obtained for the investigated compounds reveal interesting results, as follows: in HAp there are present $\mathrm{Ca}, \mathrm{P}$ and $\mathrm{O}$ in its structure, with a $\mathrm{Ca} / \mathrm{P}$ ratio of 1.67; specific peaks of gold have been identified in AuHAp, higher at AuHAp than $\mathrm{Au}$ alone; there were no significant elements detected apart from those elements, which confirms the high purity of nanocrystalline AuHAp powder, Fig. 3.

Visually, the formation of nanoparticles was evidenced by color changes of mixed solutions, due to excitation of surface plasmon vibrations in the metal nanoparticles and could be evidenced by UV-Vis spectrophotometry (Fig. 4). HAp does not have specific absorption bands in the visible range, and by treating the wood with HAp and 


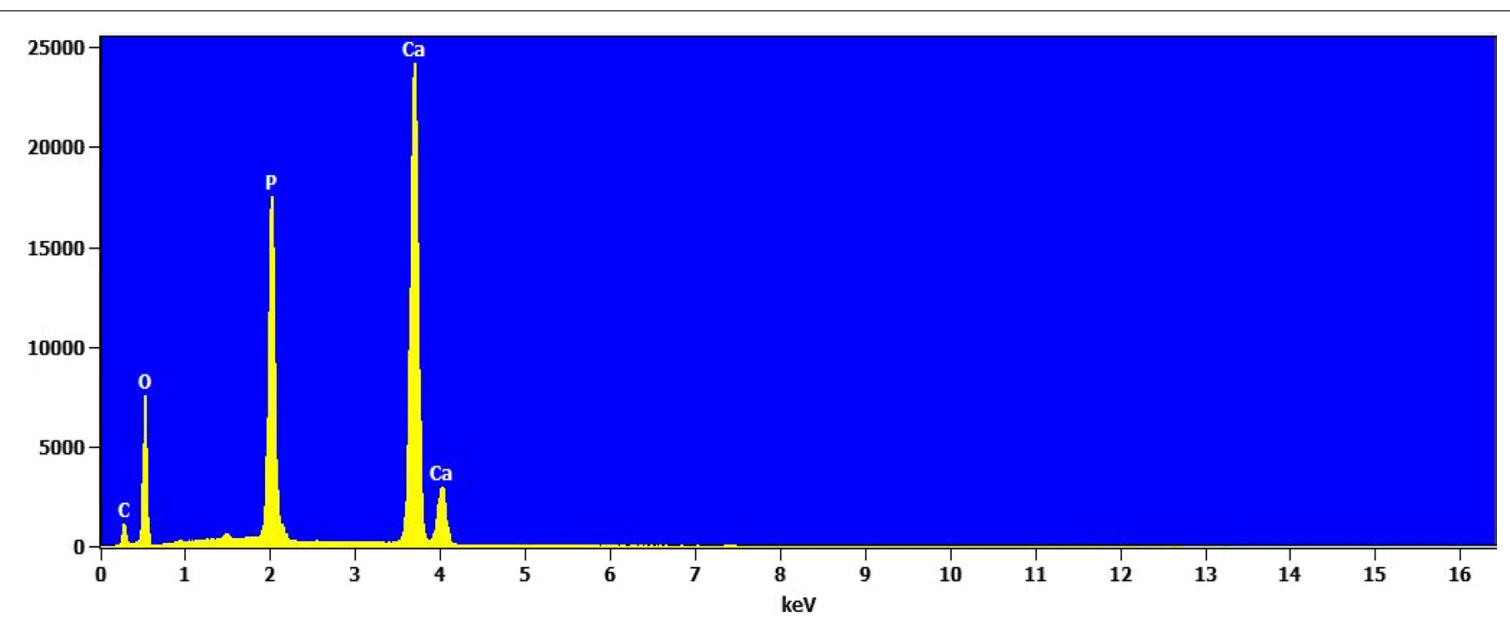

HAp
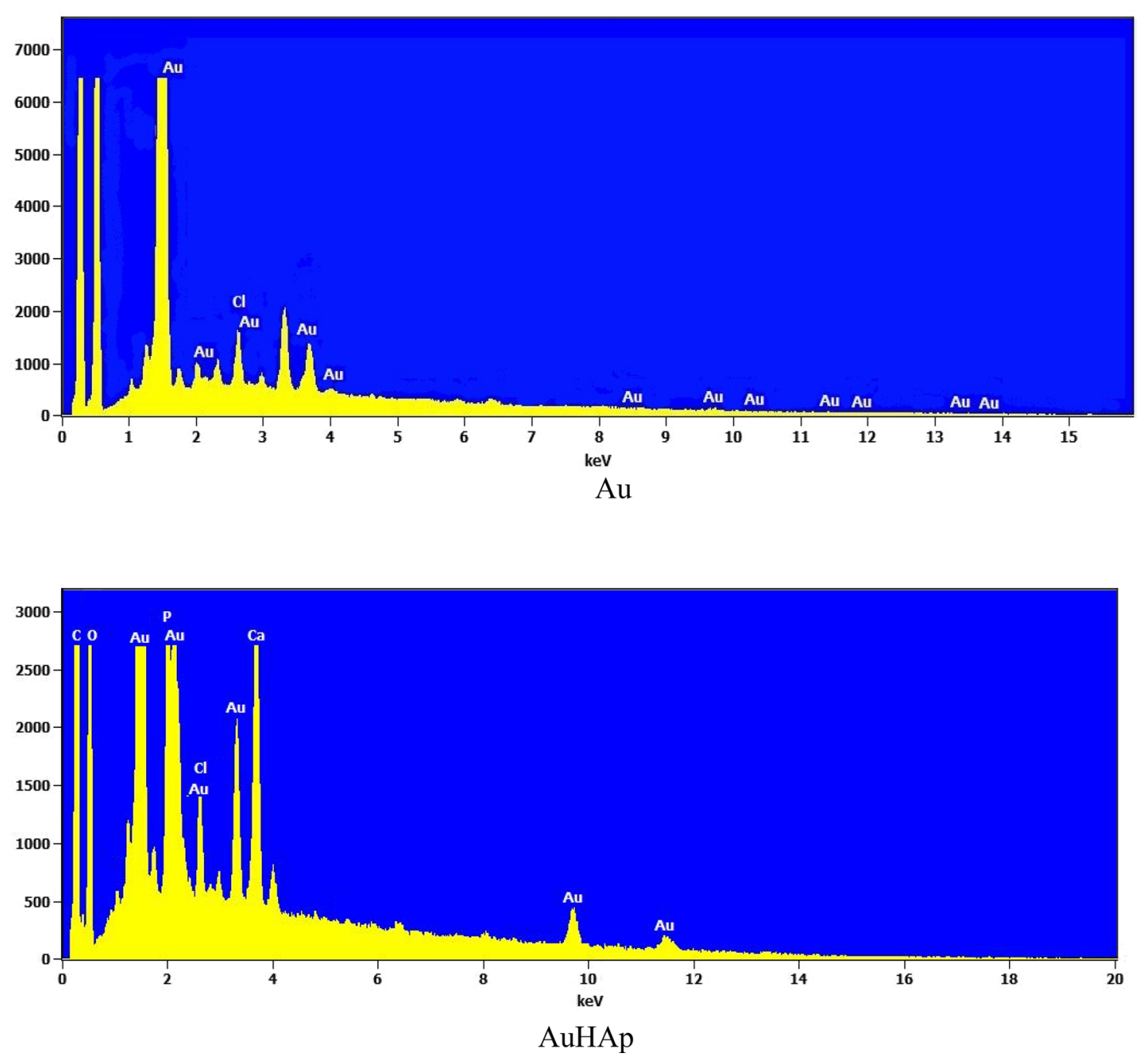

Fig. 3 The EDS diagrams of HAp, Au nanoparticles and AuHAp 


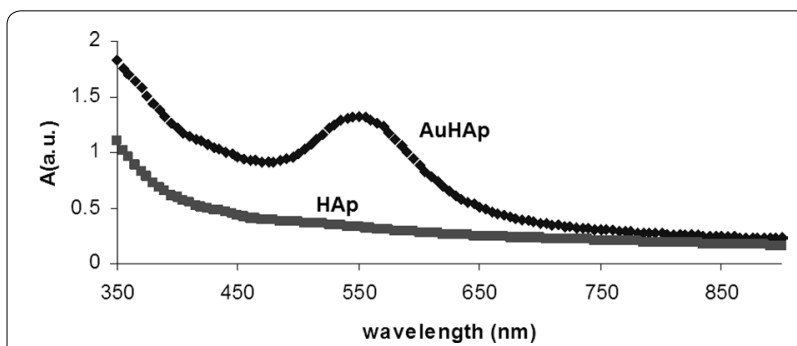

Fig. 4 The UV-Vis spectra of HAp and AuHAp

$\mathrm{HAuCl}_{4}$, a broad band appears in the absorption spectrum at $520 \mathrm{~nm}$, the band which could be assigned to AuHAp, being known that the specific band of the gold nanoparticle is positioned at $540 \mathrm{~nm}$. Simultaneously, the band from 280 to $290 \mathrm{~nm}$, specific to the aromatic character of the lignin, is diminished by forming gold nanoparticles and due to their interaction with hydroxyapatite, resulting AuHAp [13, 28].

If the $\mathrm{Au}$ nanoparticles generated on the wood in the absence of HAp, are let to stay for a longer time, they are able to form big spheres with diameters higher than $100 \mathrm{~nm}$, with a well-defined shape and with sign of agglomeration, visible by UV-Vis spectroscopy (Fig. 5) by a wide band at $645 \mathrm{~nm}$. This is a partial conclusion that Au nanoparticles should be generated in the presence of hydroxyapatite and wood in solution, in order to quickly form AuHAp.

Also, these agglomerated nanoparticles could be visualized by optical microscopy $(\times 60)$ as submicrometresized sphere-like (Fig. 6), and by SEM investigations, too, Fig. 7.

From these images, could be determined the size of the involved particles: hydroxyapatite nanoparticles with a size of $70 \mathrm{~nm}$, gold nanoparticles with a size of $50 \mathrm{~nm}$ for single particle and $2000 \mathrm{~nm}$ for aggregated forms. By means of SEM investigations, the presence

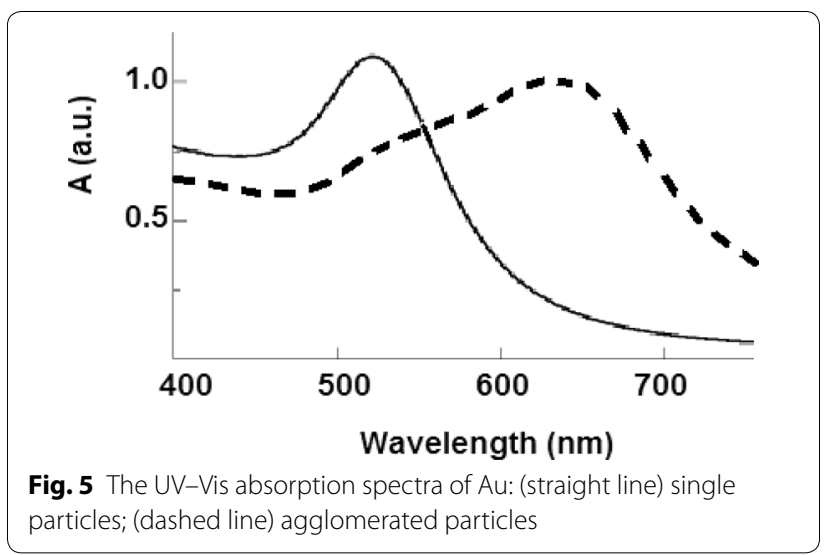

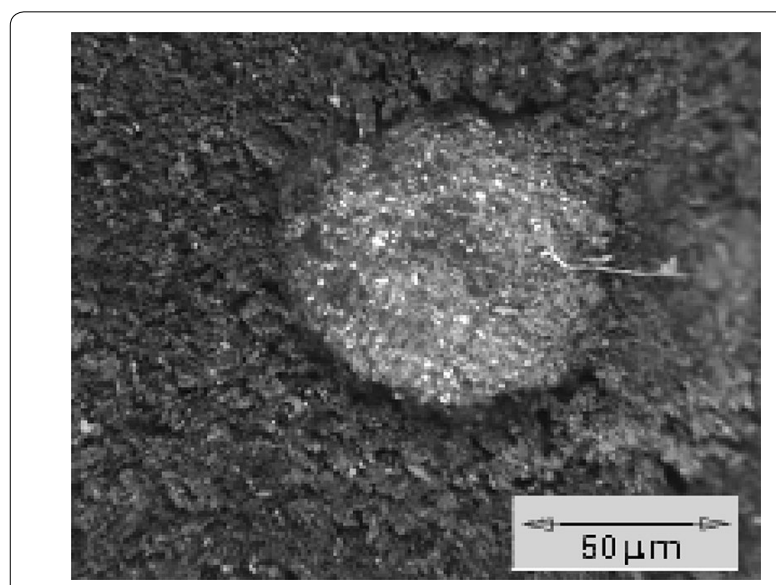

Fig. 6 The optical micrographs of Au agglomerates

of nanoparticles builders and their distribution in the wood structure could be highlighted: the consolidant was identified as lighter deposits in the three directions (transverse, tangential and radial). The new compound AuHAp is visible on the cross-sections, in vessels and fibers in the form of bulky compact areas $(100 \times$ magnification). In tangential sections, the presence of the composite was confirmed by deposits as white spots in punctuation (400× magnification). In radial sections, the consolidator was seen in the form of deposits in the pots and in the punctuation elements $(100 \times$ magnification). A well distributed and uniform layer consisting from AuHAp systems with a network aspect are observed, which covers the wood vessels and fibers, stopping the wood weathering process (Fig. 8a-d).

In the same manner, the Fourier transformed infrared spectra evidenced the chemical modification of wood through the reaction with nanoparticles. The spectrum of hazelnut wood showed similar bands as all the wood samples: strong broad OH stretching (3300$\left.4000 \mathrm{~cm}^{-1}\right), \mathrm{C}-\mathrm{H}$ stretching in methyl and methylene groups $\left(2800-3000 \mathrm{~cm}^{-1}\right)$, and a strong broad band in the region from 1000 to $1750 \mathrm{~cm}^{-1}$ assigned to lignin, which corresponds to $\mathrm{CO}$ bending vibrations of guaiacyl ring and $\mathrm{C}=\mathrm{C}$ stretching vibrations in aromatic rings. The enhanced carbonyl absorption peak at $1735 \mathrm{~cm}^{-1}, \mathrm{C}-\mathrm{H}$ absorption at $1381 \mathrm{~cm}^{-1}\left(-/ \mathrm{C}-/ \mathrm{CH}_{3}\right)$, and $-\mathrm{C}-/ \mathrm{O}-/$ stretching band at $1242 \mathrm{~cm}^{-1}$ confirmed the formation of some bonds between the wood substrate and nanoparticles, as it was previously hypothesised. Appearance of the band near $1600 \mathrm{~cm}^{-1}$ strongly associated with the aromatic $\mathrm{C}-\mathrm{O}-\mathrm{CH}_{3}$ stretching mode, is a proof for the above hypothesis (Fig. 9), while the peak of absorption at $1512 \mathrm{~cm}^{-1}$, originating from 

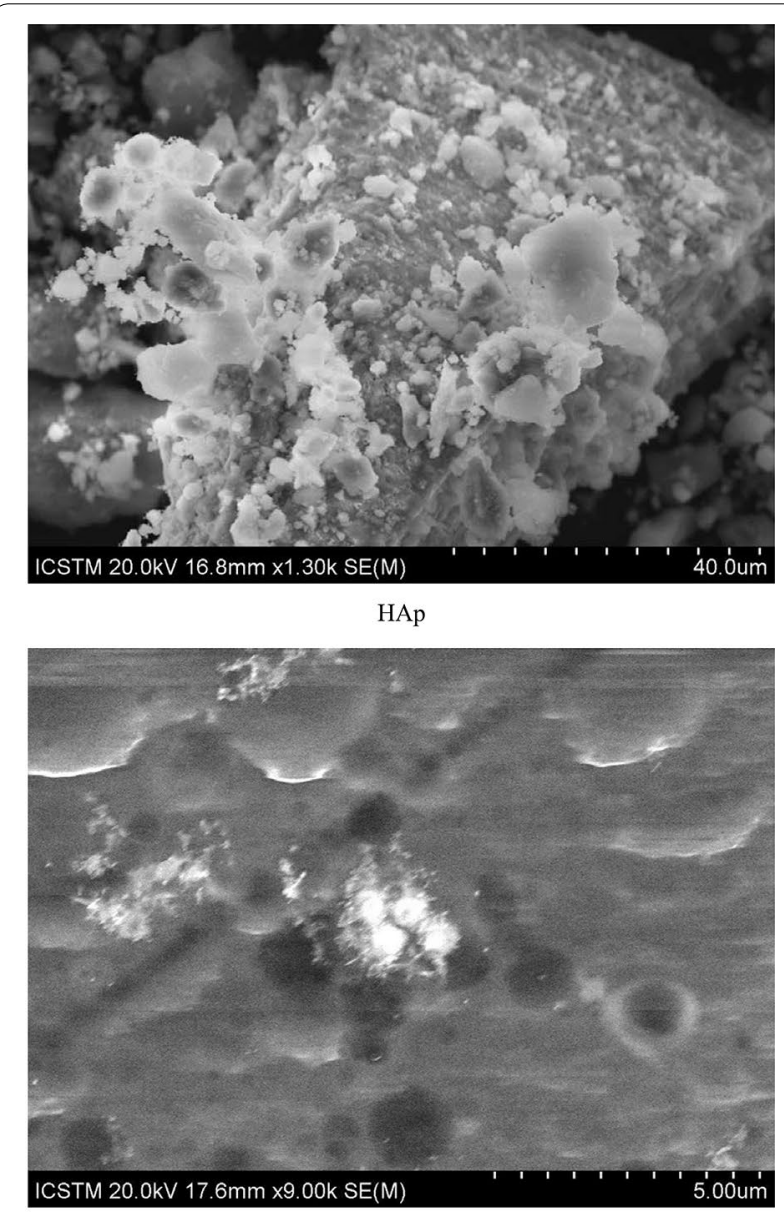

Au nanoparticles

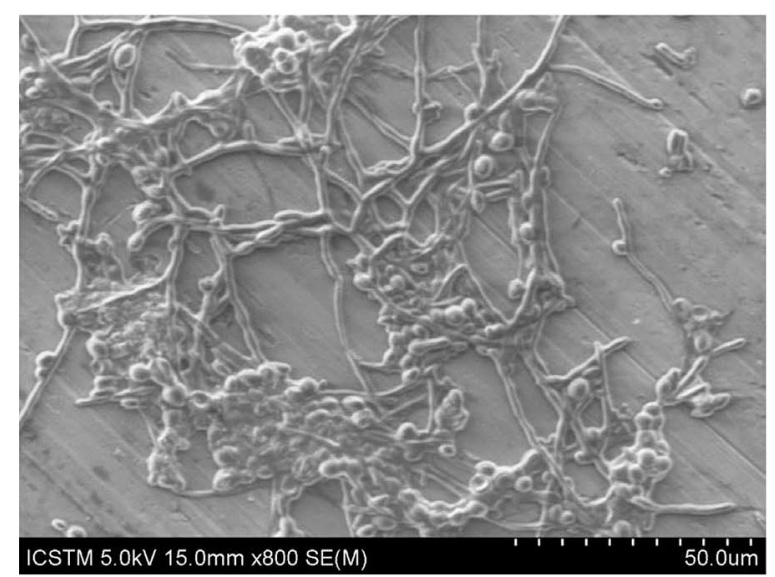

AuHAp

Fig. 7 SEM images for the investigated systems

the vibration skeleton of the aromatic benzene ring was characteristic to lignin $[29,30]$.

Figure 9 shows the FT-IR spectra of the HAp, Au and AuHAp on wood. These data clearly revealed the presence of the various vibrational modes corresponding to phosphates and hydroxyl groups. The peaks at 870 , 1035 and $1425 \mathrm{~cm}^{-1}, 566$ and $598 \mathrm{~cm}^{-1}$, were assigned to $\mathrm{PO}_{3}^{-4}$. The broad transmittance at $3450 \mathrm{~cm}^{-1}$ was attributed to the $-\mathrm{OH}$ stretching. These signals observed in the FT-IR spectrum indicated the incorporation of Au nanoparticles in HAp powder.

For the same substrate, the specific Raman bands were detected for lignin at $1600 \mathrm{~cm}^{-1}$, for cellulose glycosidic C-O-C stretching band at $1098 \mathrm{~cm}^{-1}$ and aromatic stretching band at $1605 \mathrm{~cm}^{-1}$. Except for these, the unsaturated and carbonyl groups showed a shoulder at ca. $1658 \mathrm{~cm}^{-1}$. The main origin of this band is hexenuronic acid or even ethylenic and carbonyl structures from lignin. In cellulose, the bands at 1600 and $1095 \mathrm{~cm}^{-1}$ could be assigned to unsaturated and carbonyl structures (Fig. 10). Spectral changes observed in the range of $1800-1500 \mathrm{~cm}^{-1}$ could be attributed to the hemicelluloses changes. Furthermore, the lower carbonyl band in the Raman spectra was caused by degradation products of lignin or unsaturated wood compounds. The fact that the spectrum of hydroxyapatite on wood was more intensive than the other components, and quite low for gold hydroxyapatite, are clear indications of the use of hydroxyapatite as a source for formation of metal nanoparticles [31]. Also, was observed that the vibrations of bonds in the applied nanoparticles may overlap with those of lignin structures, as a new proof of lignin participation at nanoparticles generation.

The deposition of the nanoparticles on the wood surface was monitorized by chromatic parameters change. It is well known that wood changes its color over time, and the discolorations should be a result of alterations in the chemical components [32]. Both young and aged samples were found to be darker than the young wood, while and red and yellow colors increased as well (Fig. 11).

Based on the above obtained results, from mechanistic point of view, the reduction of $\mathrm{Au}^{3+}$ to $\mathrm{Au}^{\circ}$ occurs on contact with HAp, either by electron transfer between two adjacent carbonyl groups (from the end groups of lignin from wood), or through the ability to link $\mathrm{Au}^{3+}$ with the phosphate groups from hydroxyapatite, via the reduction of $\mathrm{HAuCl}_{4}$ [33]. Hydroxyapatite has a highly adsorptive surface due to the polar $\mathrm{OH}^{-}$groups and has a similar structure with an ion exchanger, Fig. 12.

The color varies from the untreated sample to the $\mathrm{HAuCl}_{4}$ treated one and is less colored than treated with $\mathrm{HAuCl}_{4}$ and $\mathrm{HAp}$ (Fig. 13). The determinations have been achieved for wood samples treated with gold, hydroxyapatite and gold hydroxyapatite on the wood surface. Figure 14 shows two of the main chromatic parameters for all tested samples. The values obtained reveal that in this case $\Delta b^{*}$ is less 5 and $\mathrm{DE}^{*}$ is less than 2 only in the 

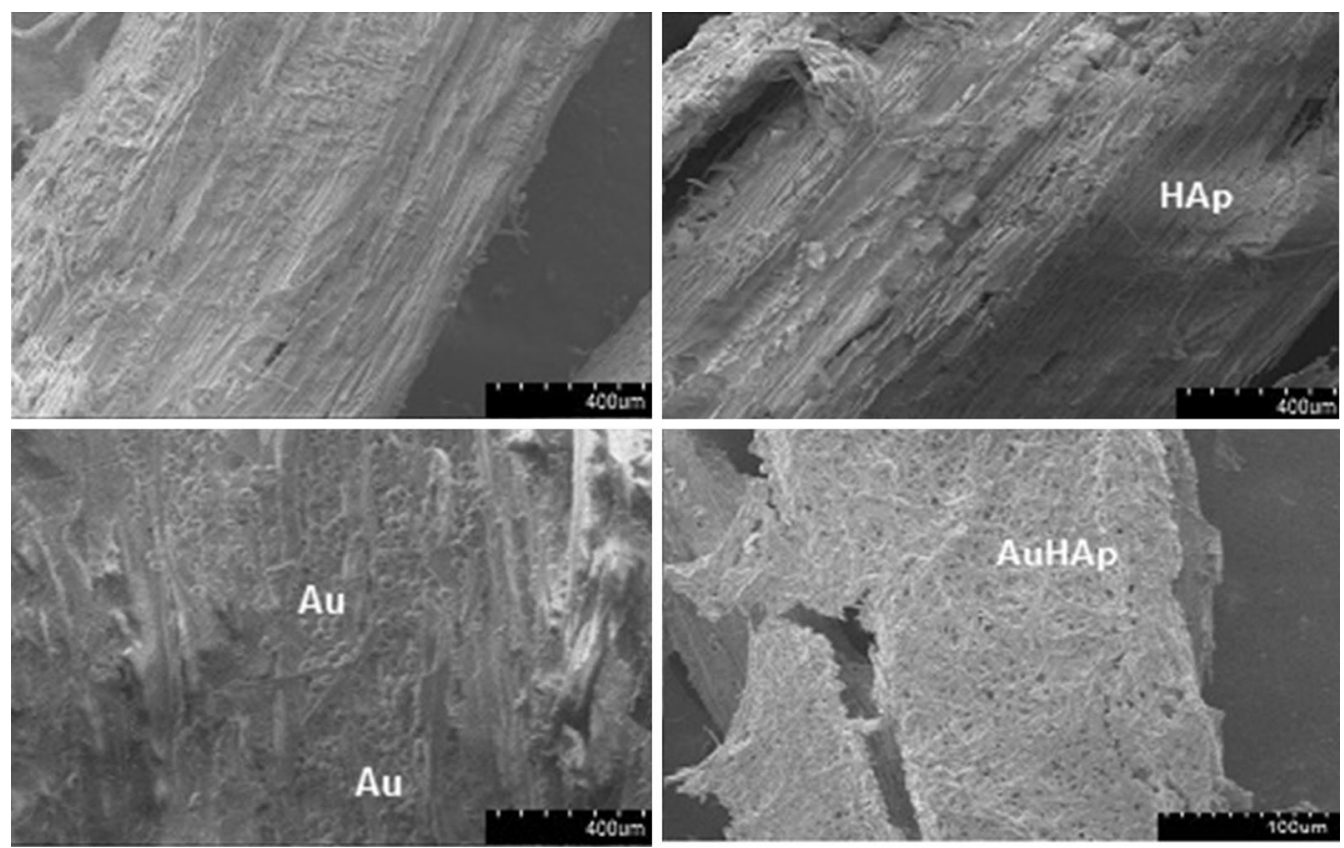

Fig. 8 SEM images of the treated wood. a Aged wood, b Aged wood wit HAp, c Aged wood with AuNP, d Aged wood with AuHAp

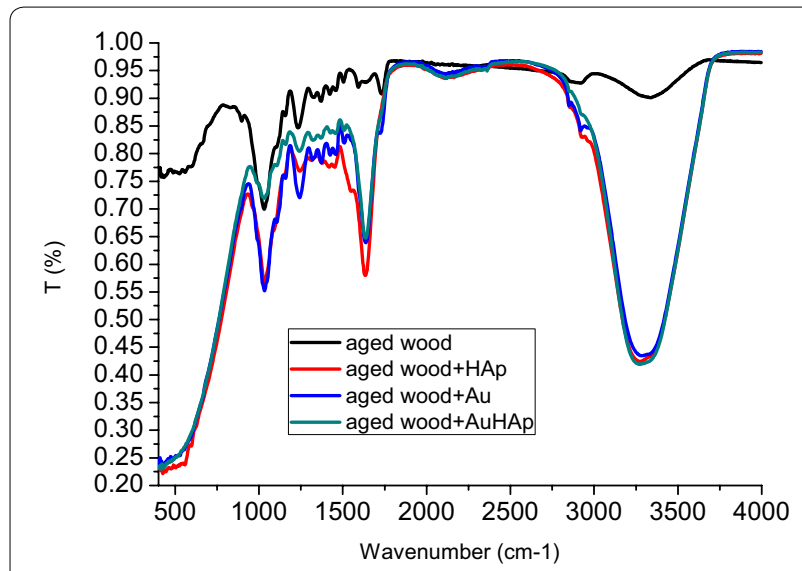

Fig. 9 The FTIR spectra of hazelnut wood treated with Au and HAp nanoparticles

case of AuHAp, as real proofs for the stability results of old wood [12].

It could be observed that the young wood was more stable than the aged one, which is absolutely normal. Also, the wood samples treated with AuHAp were more stable than those treated with gold nanoparticles. A stabilization to weathering due to the space filling network formed on the wood (AuHAp) is responsible for this statement. Various experiments demonstrated that color properties are in direct relation to aging, similar with the thermal treatment [34].

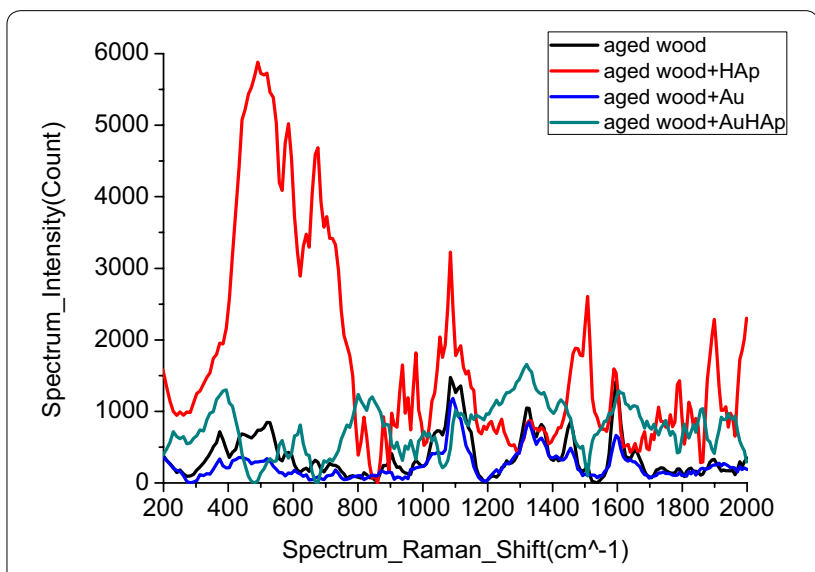

Fig. 10 The Raman spectra of hazelnut wood treated with Au, HAp and AuHAp nanoparticles

The tests were performed with a Silver Schmidt L Hammer, adapted for wood tests, is in agreement with literature [35]. The surface hardness for the treated specimens, presented in Table 1, indicates that the hardness of wood varies with the direction of the wood grain, and is higher for the wood treated with AuHAp. Testing on the surface of a plank, perpendicular to the grain, the value is determined by the size of the indention made in the wood-the harder the wood, the higher the surface hardness value. 


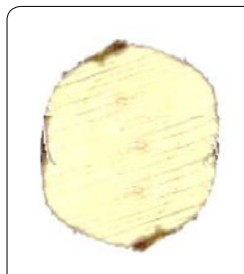

Young wood

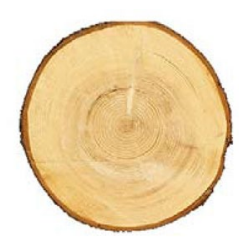

Aged wood

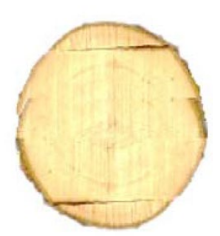

Aged wood + HAp
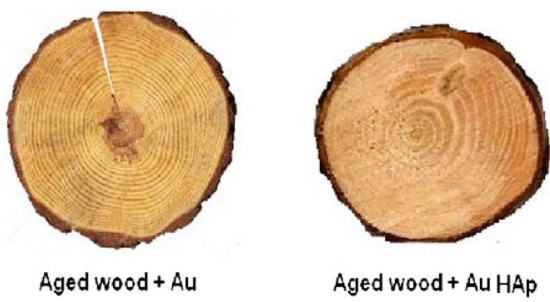

Fig. 11 Wood slices untreated and treated with the investigated nanosystems

Surface hardness is the one of most important indices reflecting the quality of the wood. The surface hardness increases in an almost linear way with increasing density.

The obtained results argued very well the above mentioned results: gold nanoparticles have the capacity to insert in the wood channels along the micro fibrils, with local agglomerated formations, preservating the wood. Also, in comparison with hydroxyapatite the surface hardness of AuHAp increased, due to the fibers network generated on the wood surface, argued by the above investigations.

Hazelnut is a local white hardwood with a density between 0.6 and $0.7 \mathrm{~g} / \mathrm{cm}^{3}$. It is hygroscopic, with an accentuated flexibility and easy to model it. In this wood type, water is found in three different forms: constitution water-6\% due to chemical reactions, bound water-30\% at the saturation point of the fibers, responsible for wood swelling (hard to be removed) and free capillary water-more than $30 \%$ (easy to be removed). The changes of the wood humidity are presented in Fig. 14, where it could be observed that AuHAp strongly decrease the humidity.

Hygroscopic materials, such as wood and woodbased materials, have an ability to adsorb and desorb moisture with the variations of surrounding conditions, due to their free hydroxyl groups in the cell wall When wood absorbs moisture from the external environment it form hydrogen bonds or release moisture through the cutting of hydrogen bonds. Under such context, the hysteresis effect in the sorption and desorption of water vapor by wood has been different explained as a consequence of differences in (1) the availability of bonding

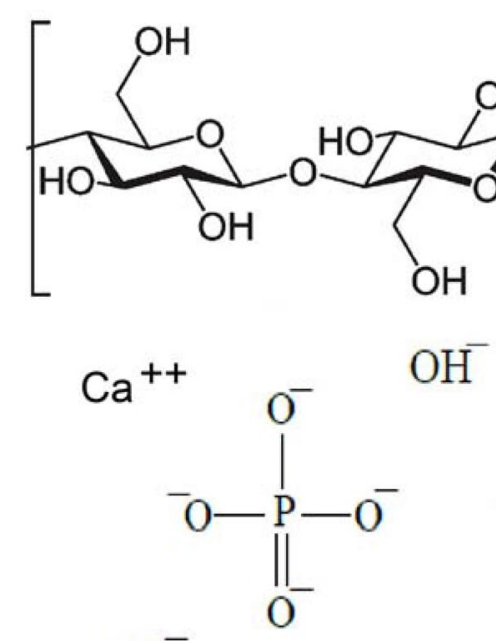

$\mathrm{OH}^{-}$

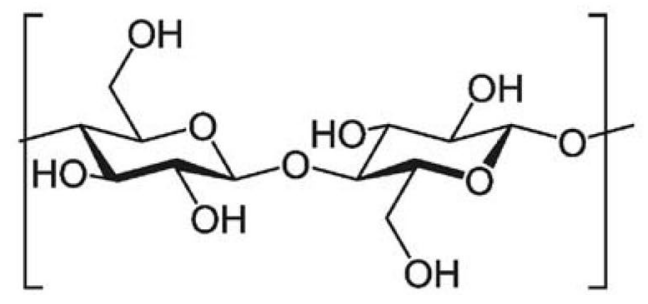

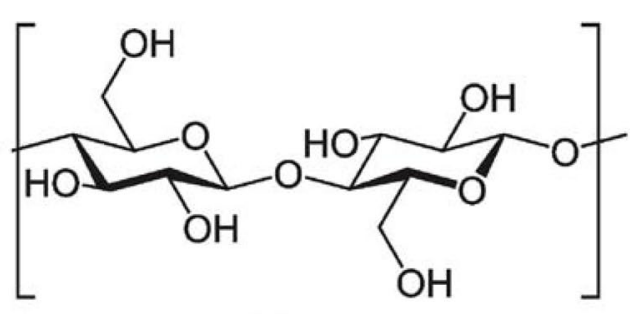

$\mathrm{OH}$
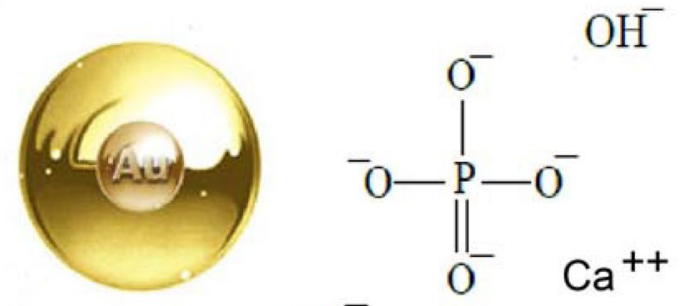

$\mathrm{OH}^{-}$

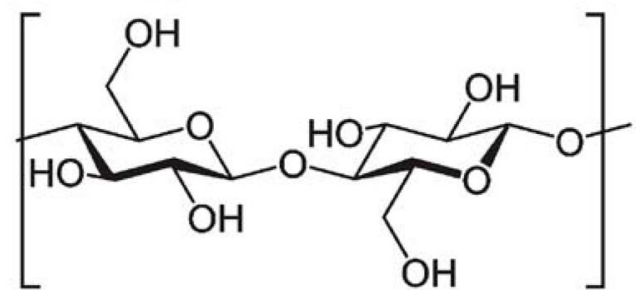

Fig. 12 The schematic structure of AuHAp on wood 


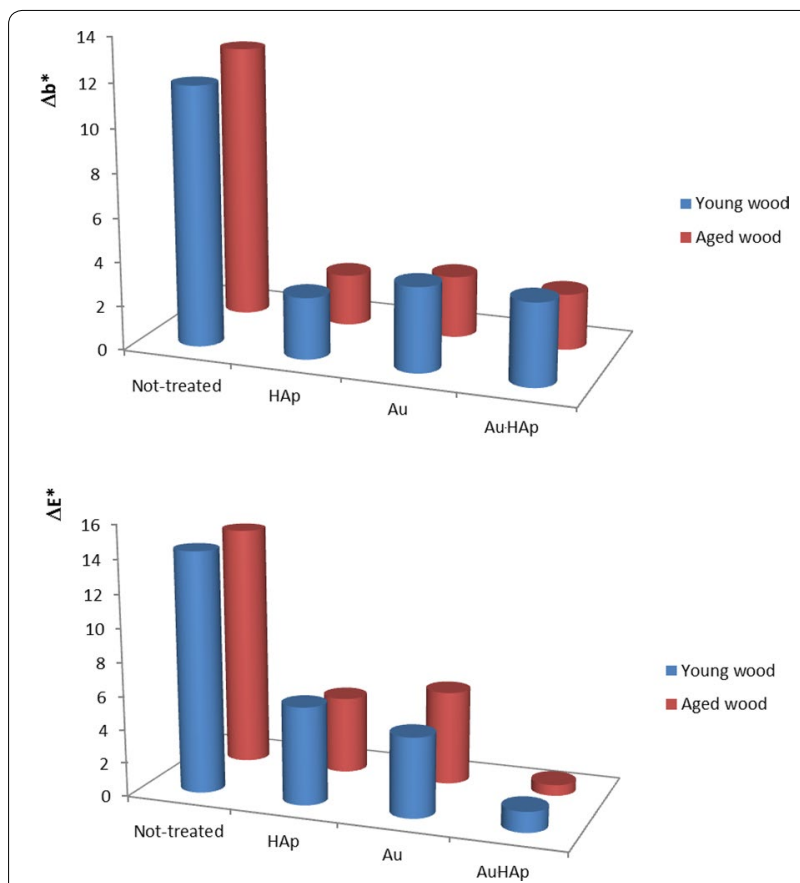

Fig. 13 The chromatic parameter $\Delta b^{*}$ (up) and $\Delta E^{*}$ (down) for wood treated with HAp, Au and AuHAp

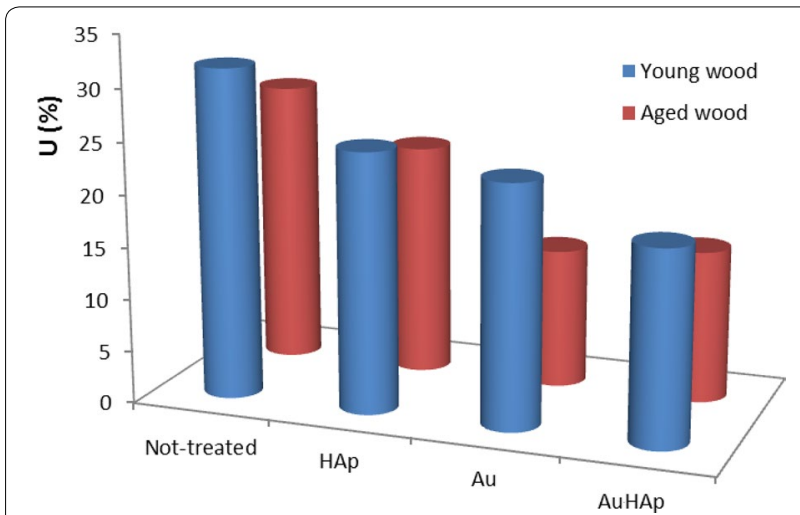

Fig. 14 The humidity changes for hazelnut wood in different conditions

Table 1 Surface hardness for the treated specimens

\begin{tabular}{lr}
\hline Sample & SH (N/ $\left.\mathbf{m}^{\mathbf{2}}\right)$ \\
\hline Aged wood & $29 \pm 1.2$ \\
Aged wood + HAp & $35.8 \pm 1.7$ \\
Aged wood + Au & $34 \pm 1.8$ \\
Aged wood + AuHAp & $37.1 \pm 2.9$ \\
\hline
\end{tabular}

SH surface hardness sites for sorption on molecular surfaces, (2) the degree of aggregation of a swelling or shrinking cellulosic gel system, and (3) the wettability of submicroscopic capillaries within the cell wall. The hysteresis shows sigmoid isotherms is to a considerable degree a phenomenon of capillary condensation. The hysteresis between the sorption and desorption isotherms for young and aged hazelnut was very similar, the hysteresis decreased with increasing relative humidity of the atmosphere, more accentuated for AuHAp than all the other systems, Fig. 15.

Hysteresis indicates less water retention of dried capillaries as compared to those in the wet state, due to the fact that the wood suffer some deformations during sorption. The phenomenon of hysteresis of wood is due to the changes (tensions and deformations) of the components of the wood as well as to the variations of the water vapor that cause swelling due to the molecular and capillary sorption processes. The degree of the hysteresis was calculated according to Eq (4) and evaluate the extent of specific structural change.

Degree of Hysteresis $=100 \times($ Mdesorption - Msorption $)$

$$
\text { /Msorption }
$$

The values of hysteresis decrease at young wood and increase at aged wood, due to an incomplete rehydration of sorption sites during a subsequent sorption cycle, and effect of compressive stresses during swelling, more strongly at aged wood AuHAp than the other systems, which generates the network able to cover and protect the wood surface, in good agreement with literature data [36]. The sorption behaviour of wood is dependent upon the previous exposure of the wood to atmospheric relative humidity. During sorption, water molecules penetrate the cell wall matrix (composed of lignin and hemicellulosic polysaccharide) in which the cellulose are embedded. This results in the formation of nanopores within the matrix. The extent of the hysteresis clearly decreases with increasing relative humidity, which suggests that the fiber structure strongly changes when moisture adsorbs on the dry fiber or reversely when all moisture desorbs from the fiber. The hysteresis is calculated as the difference between $M_{\text {inf(total in desorp.) }}$ and $M_{\text {inf(total in sorp.) }}$ that are the absolute equilibrium mass values of adsorbed water in the material of the desorption and sorption process respectively at the same relative humidity. However, this value could include the effect of moisture contents in the wood.

The difference may be a result of the lower crystallinity observed at the aged sample. However, based on 

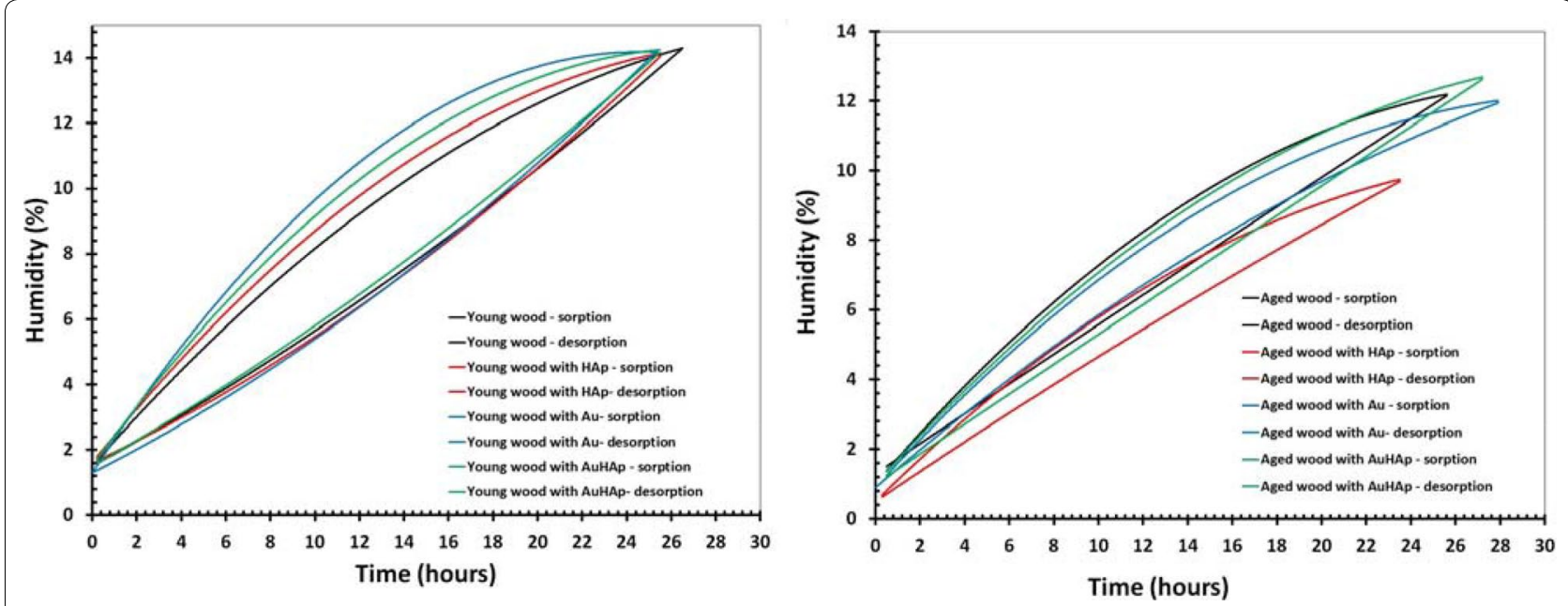

Fig. 15 The hysteresis for young and aged wood samples

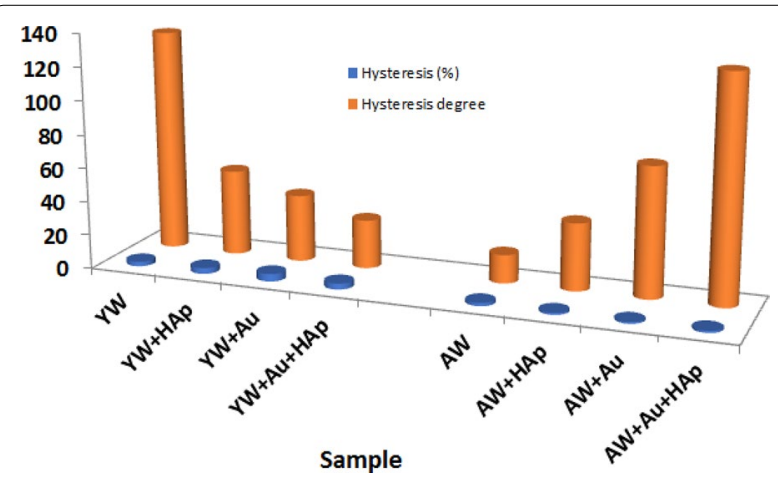

Fig. 16 The graphic representation of hysteresis and hysteresis degree for young (YW) and aged wood (AW) higher hysteresis coefficients, could be supposed that aged wood is more hygroscopically stable than young wood, Fig. 16. This rules is stronger for AuHAp.

\section{Conclusions}

In this paper it is proposed a new nanosystem goldhydroxyapatite (AuHAp), tested on the hazelnut wood samples (young and aged specimens), as a new solution for preservation of some wooden artifacts. This paper addresses a broad range of analytical methods: X-ray diffraction (XRD), UV-Vis spectrophotometry, Fourier transformed infrared spectroscopy (FTIR), Raman spectroscopy, scanning electron microscopy with energy dispersive spectroscopy (SEM-EDS), chromatic parameters and hardness test. Also, humidity sorption/desorption measurements are used for humidity sorption and desorption studies. The adsorption and desorption tests determine the hydroscopic sorption properties of the wood specimens by measuring the mass of the specimens in equilibrium with air at a specific temperature and $\mathrm{RH}$. All the results concluded that after the application of the new system on the hazelnut wood surface, a well distributed and uniform layer consisting from AuHAp systems with a network aspect are observed, which covers the wood vessels and fibers, filling the voids and stopping the wood weathering process, more accentuated at aged wood than at the young species. The extent of the hysteresis decreases with increasing relative humidity, which suggests that the fiber structure strongly changes when moisture adsorbs on the dry fiber or reversely when all moisture desorbs from the fiber.

\section{Abbreviations}

SEM-EDS: scanning electron microscopy with energy dispersive spectroscopy; XRD: X-ray diffraction; FTIR: Fourier transformed infrared spectroscopy; Au: gold; HAp: hydroxyapatite; AuHAp: gold hydroxyapatite; $\triangle \mathrm{b}$ : coloring density; $\mathrm{HAuCl}_{4}$ : tetrachloroauric acid.

\section{Authors' contributions}

RMI, IRSB, NN, TN and RMG designed and performed the research. IRSB and LI performed the extraction. AG performed the XRD and XRF analyses. ST, RMS and IDD performed the SEM-EDS, Raman and FTIR analyses. RMI, IRSB and TN wrote and corrected the manuscript. All authors reviewed the manuscript. All authors contributed equally to this work. All authors read and approved the final manuscript.

\section{Author details}

${ }^{1}$ Research Group "Evaluation and Conservation of Cultural Heritage", National R\&D Institute for Chemistry and Petrochemistry-ICECHIM, 202 Splaiul Independentei, 060021 Bucharest, Romania. ${ }^{2}$ Doctoral School of Materials Engineering, Valahia University of Târgoviște, Târgoviște, Romania. ${ }^{3}$ Department of Chemistry, Rhodes University, Grahamstown 6140, South Africa. ${ }^{4}$ Multidisciplinary Science and Technology Research Institute-ICSTM-UVT, Valahia University of Târgoviște, 13 Aleea Sinaia, Târgoviște, Romania. 


\section{Acknowledgements}

The authors are grateful to the financial support of the projects: PN

11BM/2016 and PN-III-P1-1.2-PCCDI-2017-0476 from UEFISCDI-MECI, Romania.

\section{Competing interests}

The authors declare that they have no competing interests.

\section{Availability of data and materials}

All the data supporting the conclusions are included within the article.

\section{Funding}

This paper received the financial support of the projects: PN 11BM/2016 and 51PCDDI/2018 from UEFISCDI-MECI, Romania. The funding body played no role in the design of the study and collection, analysis, and interpretation of data and in writing the manuscript.

\section{Publisher's Note}

Springer Nature remains neutral with regard to jurisdictional claims in published maps and institutional affiliations.

Received: 3 February 2018 Accepted: 4 June 2018

Published online: 18 June 2018

\section{References}

1. Nilson T, Rowell R. Historical wood-structure and properties. J Cult Herit 2012. https://doi.org/10.1016/j.culher.2012.03.016.

2. Richardson BA. Wood preservation. London: E. \& F.N. Spon; 1993.

3. Chapman S, Mason D. Literature review: the use of paraloid B-72 as a surface consolidant for stained glass. J Am Inst Conserv. 2003;42(2):381-92.

4. Cataldi A, Deflorian F, Pegoretti A. Microcrystalline cellulose filled composites for wooden artwork consolidation: application and physicmechanical characterization. Mater Des. 2015;83:611-9.

5. Traistaru AAT, Timar MC, Campeanu M, Croitoru C, Sandu I. Paraloid B72 versus Paraloid B72 with Nano-ZnO additive as consolidants for wooden artifacts. Mater Plast. 2012;49(4):293-300.

6. Timar MC, Sandu ICA, Beldean E, Sandu I. FTIR investigation of Paraloid B72 as consolidant for old wooden artefacts_-principle and case studies. Mater Plast. 2014:51(4):382-7.

7. Tuduce Traistaru A-A, Sandu ICA, Timar MC, Dumitrescu GL, Sandu I. SEMEDX, water absorption, and wetting capability studies on evaluation of the influence of nano-zinc oxide as additive to paraloid B72 solutions used for wooden artifacts consolidation. Microsc Res Tech. 2013;76(2):209-18.

8. Crisci GM, La Russa MF, Malagodi M, Ruffolo SA. Consolidating properties of Regalrez 1126 and Paraloid B72 applied to wood. J Cult Herit. 2010;11(3):304-8.

9. Lionetto F, Frigione M. Effect of novel consolidants on mechanical and absorption properties of deteriorated wood by insect attack. J Cult Herit. 2012;13(2):195-203.

10. Horie V. Materials for conservation: organic consolidants adhesives and coatings. Burlington: Elsevier; 2010.

11. Baglioni P, Giorgi R. Soft and hard nanomaterials for restoration and conservation of cultural heritage. Soft Matter. 2006. https://doi.org/10.1039/ b516442g.

12. Ion RM, Doncea SM, Ion ML, Rǎdiţoiu V, Amǎriuţei V. Surface investigations of old book paper treated with hydroxyapatite nanoparticles. Appl Surf Sci. 2013. https://doi.org/10.1016/j.apsusc.2013.07.159.

13. Ion RM, Turcanu-Caruţiu D, Fierăscu RC, Fierăscu I, Bunghez IR, Ion ML, Teodorescu S, Vasilievici G, Rădiţoiu V. Hydroxyapatite composition as consolidating material for the chalk stone from Basarabi-Muratlar churches ensemble. Appl Surf Sci. 2015. https://doi.org/10.1016/j.apsus c.2015.08.196

14. Johnston JH, Nilsson T. Nanogold and nanosilver composites with lignincontaining cellulose fibers. J Mater Sci. 2012. https://doi.org/10.1007/ s10853-011-5882-0.

15. Ding $Y$, Liu J, Wang $H$, Shen $G, Y u$ R. A piezoelectric immunosensor for the detection of alpha-fetoprotein using an interface of gold/hydroxyapatite hybrid nanomaterial. Biomaterials. 2007. https://doi.org/10.1016/j.bioma terials.2006.12.025.
16. Santos CF, Gomes PS, Almeida MM, Willinger MG, Franke RF, Fernandes $\mathrm{MH}$, Costa ME. Gold-dotted hydroxyapatite nanoparticles as multifunctional platforms for medical applications. Nanotechnology. 2015. https:// doi.org/10.1039/C5RA11978B

17. Gupta Y, Mathur GN, Verma S. Biomimetic synthesis and ultrastructural characterization of a zerovalent gold-hydroxyapatite composite. Bioorg Med Chem Lett. 2006. https://doi.org/10.1016/j.bmcl.2005.09.074.

18. Arumugan S, Rajam AM, Natarajan N, Rao U, Rose C, Sastry TP. Formation of gold nanoparticles on hydroxyapatite surface for enhancement of blood compatibility via a negative cilia concept. J Biomed Nanotechnol. 2000. https://doi.org/10.1166/jbn.2006.009.

19. Remant Bahadur KC, Aryal S, Bhattarai SR, Bhattarai N, Kim CH, Kim HY. Stabilization of gold nanoparticles by hydrophobically-modified polycations. J Biomat Sci Polymer Edn. 2006. https://doi.org/10.1163/15685 6206776986279.

20. Fierascu RC, Fierascu R, Somoghi R, lon RM, Moanta A, Avramescu SM, Damian CM, Ditu LM. Tuned apatitic materials: synthesis, characterization and potential antimicrobial applications. Appl Surf Sci. 2017. https://doi. org/10.1016/j.apsusc.2017.08.087.

21. Poinescu RM, Ion RM, Van Staden JF, Van Staden R, Ghiurea M. Investigations on hydroxyapatite powder obtained by wet precipitation. In: Proceedings of SPIE, advanced topics in optoelectronics, microelectronics, and nanotechnologies V, 78210B (3 December 2010). 2010. https:// doi.org/10.1117/12.882148

22. Bumbudsanpharoke $\mathrm{N}$, Ko S. In situ green synthesis of gold nanoparticles using unbleached kraft pulp. Bioresources. 2015. https://doi.org/10.1166/ jnn.2016.11902

23. Japanese Industrial Standard Committee. JIS Z 8729. Colour specificationCIELAB and CIELUV colour spaces. 4th ed. Tokyo: Japanese Standards Association (JSA); 2008

24. Hannachi S, Guetteche MN. Review of the ultrasonic pulse velocity evaluating concrete compressive strength on site. Turkey: University of Istanbul, Scientific cooperation international workshops on engineering branches; 2014.

25. ASTM D6789-02 - Test method for accelerated light aging of printing and writing paper by xenon-arc exposure apparatus. 2007.

26. Tolvaj L, Varga D, Papp G. Colour measurement for determining the steaming properties of wood. Óbuda Univ eBull. 2012;3:99-104.

27. Ya O, Uryupina VV, Vysotskii VV, Matveev VV, Gusel'nikova AV, Roldughin VI. Production of gold nanoparticles in aqueous solutions of cellulose derivatives. Colloid J. 2011. https://doi.org/10.1134/S1061933X1103015X.

28. Meejoo S, Maneeprakorn W, Winotai P. Phase and thermal stability of nanocrystalline hydroxyapatite prepared via microwave heating. Thermochim Acta. 2006. https://doi.org/10.1016/j.tca.2006.04.013.

29. Moore AK, Owen NL. Infrared spectroscopic studies of solid wood. Appl Spectrosc Rev. 2001. https://doi.org/10.1081/ASR-100103090.

30. Schwanninger $M$, Rodrigues JC, Pereira $H$, Hinterstoisser B. Effects of short-time vibratory ball milling on the shape of FT-IR spectra of wood and cellulose. Vibr Spectrosc. 2004. https://doi.org/10.1016/j.vibsp ec.2004.02.003

31. Vukomanović M, Žunič V, Otoničar M, Repnik U, Turk B, Škapin SD Suvorov D. Hydroxyapatite/platinum bio-photocatalyst: a biomaterial approach to self-cleaning. J Mater Chem. 2012. https://doi.org/10.1039/ C2JM00136E.

32. Hon DNS, Chang ST, Feist WC. Protection of wood surfaces against photooxidation. J Appl Pol Sci. 1985. https://doi.org/10.1002/app.1985.07030 0410.

33. Bunghez IR, Dumitrescu O, Somoghi R, lonita I, lon RM. Silver nanoparticles obtained via morus nigra extract synthesis and antioxidant activity. Rev Chim (Bucharest). 2015:66:112-5.

34. Rowell RM, Ibach RE, McSweeny J, Nilsson T. Understanding decay resistance, dimensional stability and strength changes in heat-treated and acetylated wood. Wood Mat Sci Eng. 2009. https://doi.org/10.1080/17480 270903261339

35. Matsuo M, Yokoyama M, Umemura K, Gril J, Yano K, Kawai S. Color changes in wood during heating: kinetic analysis by applying a timetemperature superposition method. Appl Phys A. 2010. https://doi. org/10.1007/s00339-010-5542-2.

36. Siau JF. Transport processes in wood. New York: Springer-Verlag; 1984. p. 245. 